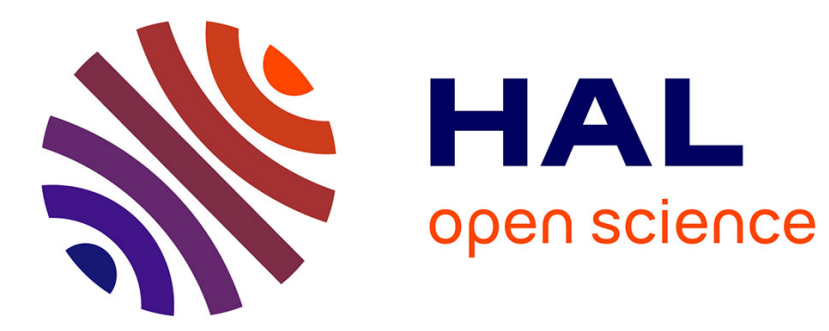

\title{
Determination of the characteristics of agglomerates in aqueous suspensions using nonlinear optimization
}

\author{
J. Bongono, N. Azema, A. Johannet, P. Gaudon
}

\section{To cite this version:}

J. Bongono, N. Azema, A. Johannet, P. Gaudon. Determination of the characteristics of agglomerates in aqueous suspensions using nonlinear optimization. Powder Technology, 2011, 208 (2), pp.271-278. 10.1016/j.powtec.2010.08.016 . hal-02949486

\section{HAL Id: hal-02949486 \\ https://hal.science/hal-02949486}

Submitted on 25 Mar 2021

HAL is a multi-disciplinary open access archive for the deposit and dissemination of scientific research documents, whether they are published or not. The documents may come from teaching and research institutions in France or abroad, or from public or private research centers.
L'archive ouverte pluridisciplinaire HAL, est destinée au dépôt et à la diffusion de documents scientifiques de niveau recherche, publiés ou non, émanant des établissements d'enseignement et de recherche français ou étrangers, des laboratoires publics ou privés. 


\title{
Determination of the characteristics of agglomerates in aqueous suspensions using nonlinear optimization
}

\author{
J. Bongono, N. Azema*, A. Johannet, P. Gaudon \\ Centre des Matériaux de Grande Diffusion, Ecole des Mines, 6 avenue de Clavières, 30319 Alès, Cédex, France
}

\begin{abstract}
A B S T R A C T
Measurement of characteristics of particles in suspensions without dilution has a practical interest in formulation, mineral processing, material sciences and environmental technologies.

These characteristics are the size, shape, and surface properties of the primary particles, and also the size, structure and the number of primary particles in the agglomerates.

In this work, the multiple light-scattering model through the optical analyzer, Turbiscan MA 2000 is used to determine the mean settling velocities of monodisperse glass beads and two polydisperse samples of powders, kaolin D and alumina, differing by their particle size distribution, their shape and their surface properties.

Beyond the experimental validation of theoretical and empirical predictions, the nonlinear adjustment of experimental settling data gives the number of primary particles per agglomerate and the agglomerate size. These two characteristics lead to the determination of the fractal dimension of the agglomerates. The latter was found in the range of $2.5-2.7$ for all suspensions examined. The calculation of permeability and spherical factor reveals the nonspherical impermeable agglomerates.
\end{abstract}

Keywords:

Suspensions

Settling velocity

Agglomerate

Fractal dimension

Multiple light-scattering

\section{Introduction}

Most of industrial processes involve suspensions as an intermediary of production, final products or as effluents. These suspensions are unstable and present various behaviors. Most of them are aqueous and concentrated. Their properties are dependent on primary particles, agglomerates and liquid medium characteristics which are localized at the microscopic, mesoscopic and macroscopic scales, respectively. The control of the behavior of these suspensions requires the establishment of the relationships between all the characteristics at all scales. The investigation methods vary due to the diversity of the suspensions. Each suspension seems to be specific and is considered as a particular case. Both light-scattering, monitoring and image analysis, devoted to the determination of the structural characteristics of agglomerates formed in suspensions have their limitations [1]. Blakey and James [2] show that the microscopic properties (e.g. surface charge of primary particles, their distance of separation, their size...) cannot estimate the effect of the structure on the macroscopic properties (e.g. viscosity, electrostatic stability...) of aqueous suspensions of goethite for some conditions. Determination of transversal parameters such as structural characteristic (e.g. mass fractal

\footnotetext{
* Corresponding author.

E-mail address: nathalie.azema@mines-ales.fr (N. Azema).
}

dimension, $D_{f}$ ) for all types of suspensions with a single method is a key point for rapid and accurate control of these media. Fractal dimension determines the structure of agglomerates and the suspension. This parameter is dependent on the microscopic properties of particles and liquid medium and it is well correlated with most of the usual macroscopic properties of suspension, justifying the increasing number of research concerning its determination over the last years.

In this work, we proposed an approach for the determination of the fractal dimension $D_{f}$ based on the measurement of the settling velocity and on the nonlinear optimization of the experimental settling data. The optimization of the parameters enabled the calculation of $D_{f}$. This paper includes the fundamentals on sedimentation process and particle velocity in Section 2 . The settling data is recorded with the concentrate suspensions analyzer, Turbiscan MA 2000 , the principle of which is presented in Section 3. The results including some hydrodynamic characteristics are presented in Section 4. Section 5 is devoted for the discussion.

\section{Theoretical developments}

\subsection{Sedimentation process and particle velocity}

As a suspension settles in a closed container, the concentration necessarily becomes non-uniform. A clear layer, devoid of particles, forms at the top and sediment at the bottom. In addition, concentration gradients can appear in the region above the sediment. 
The processes which convert the homogenous suspension into a suspension with two separate regions, clear liquid and sediment can be described with the following:

$\frac{\partial \phi}{\partial t}+\frac{\partial f(\phi)}{\partial x}=0$

with $0 \leq x \leq h, t>0$ and where $f(\phi)=v_{p} \times \phi$ is the flux function; $v_{p}, \phi, x$, $t$ stand for particle velocity, particle volume fraction, height of the settling column and time, respectively. Eq. (1) is considered together with the initial condition

$\phi(x, 0)= \begin{cases}0 & \text { for } x=h, \\ \phi_{0} & \text { for } 0<x<h, \\ \phi_{\max } & \text { for } x=0\end{cases}$

where it is assumed that the function $f(\phi)$ satisfies

$f(\phi) \begin{cases}=0 & \text { for } \phi \leq 0 \text { or } \phi \geq \phi_{\max } \\ <0 & \text { for } 0<\phi<\phi_{\max }\end{cases}$

The parameter $\phi_{\max }$ is the maximum solids concentration and $h$ is the height of the sample in the settling column.

Kynch [3] first formulated the theory of sedimentation process based on Eq. (1) for incompressible sediment. The basic assumption of this theory is that the particle velocity is a function of the local volume fraction of particle only, which for batch sedimentation in a close column is equivalent to state that $v_{p}=v_{p}(\phi)$.

Solving Eq. (1) by the method of characteristics [3] gives the solid volume fraction $\phi$ at any point $(x, t)$ for a given initial solid volume fraction $\phi_{0}$.

$\phi(x, t)=\phi_{0}\left(x-v_{p} t\right)$

Eq. (2) can be constructed in the plane $(x, t)$ [3]. The characteristic curves are straight lines with slope $v_{p}(\phi)$ and the value $\phi(x, t)$ remains constant along any characteristic line.

The validity of the theory of Kynch was proved in several papers but its major inconvenience is that the initial condition of the homogeneity of the suspension is difficult to meet experimentally.

The other manner is to construct a virial expansion valid to $O(\phi)$ by expressing the velocity of the ith particle through a pairwise additive approximation. The results enable exact calculations of the settling velocity $v_{p}(\phi)$ in monodisperse suspensions at dilute solid volume fraction [4-6] as given:

$\frac{v_{p}(\phi)}{v_{p, 0}}=1-6,55 \phi+O\left(\phi^{2}\right)$

The extension of higher concentration for monodisperse hard sphere suspensions is given by Eq. (4) [7] and Eq. (5) [8].

$\frac{v_{p}(\phi)}{v_{p, 0}}=(1-\phi)^{n}$

$\frac{v_{p}(\phi)}{v_{p, 0}}=\frac{1-\phi}{1+\frac{k \phi}{(1-\phi)^{3}}}$

where $\frac{v_{p}(\phi)}{v_{p, 0}}$ is the dimensionless settling velocity or settling rate, $v_{p, 0}$ is the Stokes settling velocity, $n$ in Eq. (4) and $k$ in Eq. (5) are free parameters and stand for the angular dispersion of the fluid stream lines against the vertical direction.
If the sphere are cohesive, need is to take into account the aggregation during settling. Assuming that during sedimentation, agglomerates produced are monodisperse, Valverde et al. [9] modified Eqs. (4) and (5) and showed that the resulting Eqs. (6) and (7) are valid for settling of cohesive powder.

$\frac{v_{p}(\phi)}{v_{a}}=\left(1-\phi_{e f}\right)^{n}$

$\frac{v_{p}(\phi)}{v_{a}}=\frac{1-\phi}{1+\frac{k \phi_{e f}}{\left(1-\phi_{e f}\right)^{3}}}$

with the effective agglomerate volume fraction $\phi_{\text {ef }}$ given by:

$\phi_{e f}=\frac{\rho_{0}}{N} \frac{4}{3} \pi R^{3}$

$\rho_{0}$ is the density of a particle which is the number of primary particles per unit volume of suspension.

In Eq. (7),

$v_{a}=\frac{v_{p, 0} N}{q}$

is the settling velocity of an individual agglomerate, where $q=\frac{R}{r}$ is the normalized agglomerate radius and $r$ is the primary particle radius.

The generalization to multimodal suspension is available in Ref. [10] but the variation of the coefficients with separation renders the partial differential equation difficult to solve analytically in any general sense. The semi-analytical solutions are possible for small and large values of the Peclet number [11]. Some further information is available in e.g. Ref. [12].

Eqs. (6) and (7) enable the determination of the number of primary particle $N$ per agglomerate and agglomerate radius $R$ by a nonlinear curve fitting. The fitting parameters are the agglomerate radius $R$ and the number of primary particles per agglomerate $N$. These parameters are related to the fractal dimension $D_{f}$ by Eq. (8) [13]:

$N=k_{0}\left(\frac{R_{g}}{r}\right)^{D_{f}}$

where $k_{0}$ is the fractal pre-factor and is about unity. $R_{g}$ is the radius of gyration. In Eq. ( 8 ), $R_{\mathrm{g}}$ is normalized by the primary particles radius to insure the cross-attributive of the model.

\subsection{Determination of hydrodynamic characteristics}

\subsubsection{Reynolds number}

Most of the models used in this study assume that the flow is laminar. In order to evaluate this characteristic, we used Eq. (9)

$R_{e, p}=\frac{\rho_{l} v_{a} d_{s}}{\mu}$

where $\rho_{l}, v_{a}, \mu$ and $d_{s}$ are the liquid density, agglomerate velocity in dilute suspension, liquid dynamic viscosity and area equivalent diameter, respectively.

\subsubsection{Drag coefficient and drag-corrective coefficient}

The drag coefficients $C_{D}$ for each suspension were evaluated assuming the following three cases. 
Case 1: Agglomerates are spherical, impermeable and the motion is Stokesian

$$
C_{D}=\frac{24}{\mathrm{Re}}
$$

Case 2: Agglomerates are the spherical permeable particles

$$
C_{D}=\frac{24}{\operatorname{Re}} \Omega_{\text {perm }}
$$

where $\Omega_{\text {perm }}$ is the drag-corrective coefficient. According to Vanni [14], a good approximation for $\Omega_{\text {perm }}\left(D_{f}>2\right)$ is

$$
\Omega_{p e r m}=\frac{2 \alpha^{2}\left(1-\frac{\tanh \alpha}{\alpha}\right)}{2 \alpha^{2}+3\left(1-\frac{\tanh \alpha}{\alpha}\right)}
$$

with the permeability ratio $\alpha=\frac{R}{\sqrt{p}}$, where $R$ is the outer radius of the agglomerate. $R$ is almost equal to the hydrodynamic radius $R_{i}=1.04 R_{H, i}$ [15]; $p$ is the agglomerate permeability at the agglomerate surface for which uniform porosity is [14]

$p=\frac{2 r_{1}^{2}}{9 \phi} \frac{L(\phi)}{E}$

where $L(\phi)$ and $E$ are, respectively, the Happel function and the shielding factor:

$$
\begin{aligned}
& L(\phi)=\frac{3-4.5 \phi^{1 / 3}+4.5 \phi^{5 / 3}-3 \phi^{2}}{3+2 \phi^{5 / 3}}, \\
& E=1-0.6 e^{-10 \phi} .
\end{aligned}
$$

Case 3: Drag-corrective factor depends only on the uniformity $S$ of the arrangement of the primary particles in the agglomerate and the fractal dimension $D_{\mathrm{f}}$.

$$
C_{D}=\frac{24}{\operatorname{Re}} \Omega_{S}
$$

where $\Omega_{S}=S^{\frac{1}{D_{f}}}$

$S$ is the structure factor [16] which can be determined by small angle laser scattering. It can be expressed as a function of the fractal dimension $D_{f}$, the radius of gyration $R_{g}$ of the agglomerate, the primary particle radius $r$ and the number $N$ of the primary particles in the agglomerate.

$$
\left.S=N\left(\frac{R_{g}}{r}\right)^{-1} \frac{D_{f}+2}{D_{f}}\right)^{-\frac{1}{2}} e^{-D_{f}}
$$

2.2.3. Spherical factor of particles and Peclet number

The spherical factor $\psi[15]$ and the Peclet number are expressed respectively:

$$
\begin{aligned}
& \psi=0.065 e^{\frac{1}{0.843 \Omega_{s}}} \\
& P e=\frac{2 r \Delta v_{p, 0}}{D_{0}}
\end{aligned}
$$

In Eq. (20), $\Delta v_{p, 0}$ is the relative Stokes velocity of particle with radius $r$ and $D_{0}$ is the diffusion coefficient.

Later, we will evaluate all the models listed above for all the suspensions used in this study. The goal is either to estimate the order of magnitude of these hydrodynamic characteristics for studied suspensions but also, to explain their behavior through their mesostructure.

\section{Experimental}

\subsection{Materials: powders and suspensions}

Three powders were used in our experiments: micro glass beads from Potters-Ballotini company (France), kaolin powder (type D) from Brazil and Alumina from Martinswerk (Germany). The three powders have distinct size distribution, shape, roughness and surface charge. Their main physicochemical and granular characteristics are reported in Table 1.

In order to control chemical entities in the medium and interfacial properties, dry powders of each material were dispersed in demineralized water which was obtained after crossing a double ion exchange column. The resulting suspension was stirred with a magnetic stirrer at a constant speed during $15 \mathrm{~min}$. These conditions are sufficient to insure homogeneity. Part of this homogenized suspension was introduced in a $(16 \times 125 \mathrm{~mm})$ borosilicate glass cylindrical tube and immediately analyzed in Turbiscan 2000. The sample height in the cell is $\sim 43 \pm 2 \mathrm{~mm}$. Five scans were completed for all experiments and the time elapsed between scans was maintained at 1 minute. For all experiments, the mother-suspension was prepared with $8 \mathrm{vol} \%$ solids loading and unless otherwise stated, $3.5 \mathrm{vol} \%$ and $5.7 \mathrm{vol} \%$ were used for analysis.

\subsection{Methods: turbiscan MA 2000}

The fundamentals and principles of the Turbiscan MA 2000 device are well exposed, respectively, in Bru et al. [17] , Mengual et al. [18], and Snabre \& Arhaliass's [19] works. In this section, we restrict our attention to the operating principle Fig. 1. It consists to scan by a pulse near infrared light source $(\lambda=850 \mathrm{~nm})$ a cylindrical cell containing the sample. Some of the photons undergo deviation and are scattered in all directions (scattered light). The others go through the sample

\begin{tabular}{|c|c|c|c|c|}
\hline \multirow[t]{2}{*}{ Materials } & \multicolumn{2}{|c|}{ Laser diffraction } & \multirow[t]{2}{*}{ External shape } & \multirow{2}{*}{$\begin{array}{l}\text { Electrophores is mobility } \\
(\mu \mathrm{m} . \mathrm{cm} / \mathrm{V} . \mathrm{s})\end{array}$} \\
\hline & $\mathrm{d}$ mean $(\mu \mathrm{m})$ & modes $(\mu \mathrm{m})$ & & \\
\hline Glass beads & 43.2 & 45 & spherical & -0.2 \\
\hline Kaolin D & 13.8 & $0.3-2.3-26.1$ & agglomerates of small platelets & -3.7 \\
\hline Alumina & 3.8 & $2.7-16.4$ & irregular agglomerates of small platelets & 3.2 \\
\hline
\end{tabular}
without deviation (transmitted light). The backscattered light at $135^{\circ}$ and the transmitted light at $0^{\circ}$ are registered simultaneously, step by step, every $40 \mu \mathrm{m}$ and convert into two spectra. An example of the backscattering light spectrum is shown in Fig. 2. The Y-axis corresponds to percentage of the backscattered light and the X-axis is the height of the settling cell. Every minute, a scan was performed

Table 1

Main physicochemical characteristics properties of materials examined. 


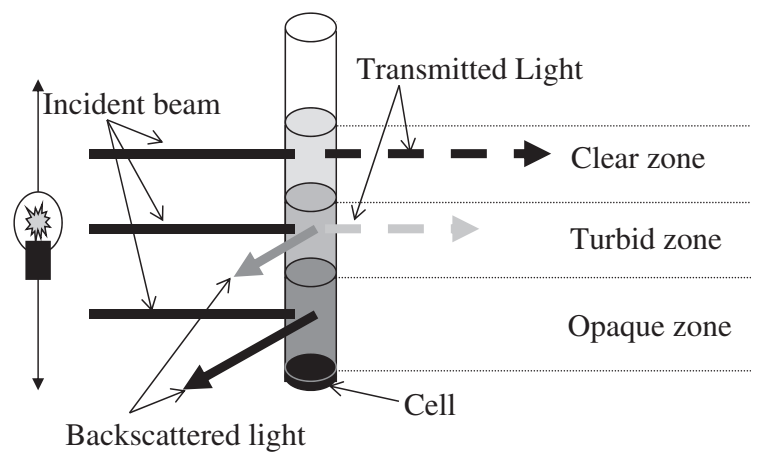

Fig. 1. Turbiscan operating principle.

along the cylindrical cell. The evolution of these signals allowed the determination the velocity of the upper interface (which corresponds to the mean settling velocity of particle $v_{p}$ ) in the way described in Section 4.1. At the bottom of the cell, the percentage of the backscattered light increased, allowing us to record the evolution of the lower interface (interface between the sediment and the bulk suspension). The evolution of both the upper interface and the lower interface depends on the characteristics of the primary particles, the agglomerates, and the suspending liquid.

\section{Results}

\subsection{Settling analysis: measurement of the mean settling velocity}

In Fig. 2, we represent an example of sedimentation profiles. At the top of the sedimentation column, the upper interface was located between the clear liquid and the bulk suspension. Its follow-up in function of time enabling the determination of the mean settling velocity. To calculate the mean settling velocity, we needed to evaluate the distance $\Delta h_{t}$ between every scans along the horizontal line H. See Fig. 2 for the position of line H. Then assuming the number of Reynolds $\operatorname{Re}<1$ and the uniform movement of the upper interface, the mean settling velocity at time $t$ can be expressed a:

$v_{p}=\frac{\Delta h_{t}}{t}$

Experimental settling data were collected from the sedimentation profiles through the mean settling velocity given by Eq. (21). These data were adjusted with the theoretical models (4), (5), (6), and (7). The results of the optimization for all materials were presented as the mean settling rate in function of particles volume fraction in Figs. 3-5. In these figures, it is clear that the particles settled initially at a constant velocity, but as the upper interface approach the bottom of settling column, the particles slowed down, indicating the formation of stresses carried by interparticle contacts. In the legends of graphs, Eqs. (4) and (6) correspond to the Richardson \& Zaki models for hard spheres and the modified Richardson \& Zaki models for cohesive particles respectively. Eqs. (5) and (7) correspond to the Mills \& Snabre models for hard spheres and modified Mills \& Snabre models for cohesive particles respectively. As we noticed it early, Eqs. (6) and (7) are the results of the modification of Eqs. (4) and (5) in order to adapt them for sedimentation of cohesive particles. Valverde and coworkers [9] are the authors of this adaptation.

\subsection{The fitting parameters}

\subsubsection{Adjustment of noncohesive models}

The only fitting parameters in Eqs. (4) and (5) were $n$ and $k$, respectively. Thus, the adjustment of noncohesive models to the experimental data was straightforward. We were expecting that the values $n=5.6$ [4] and $k=4.6$ [8] established for noncohesive particles in the dilute limit would conform to the values of $n$ and $k$ corresponding to the experimental settling data of glass beads. For cohesive materials (Kaolin D and Alumina), the values of $n$ and $k$ are expected to be different.

\subsubsection{Adjustment of cohesive models}

In the cohesive models, the fitting parameters were $n, k, R$ and $N$. The adjustment proceeded into two steps. The first step was to evaluate the free parameters $n$ and $k$ defined in Eqs. (6) and (7). The

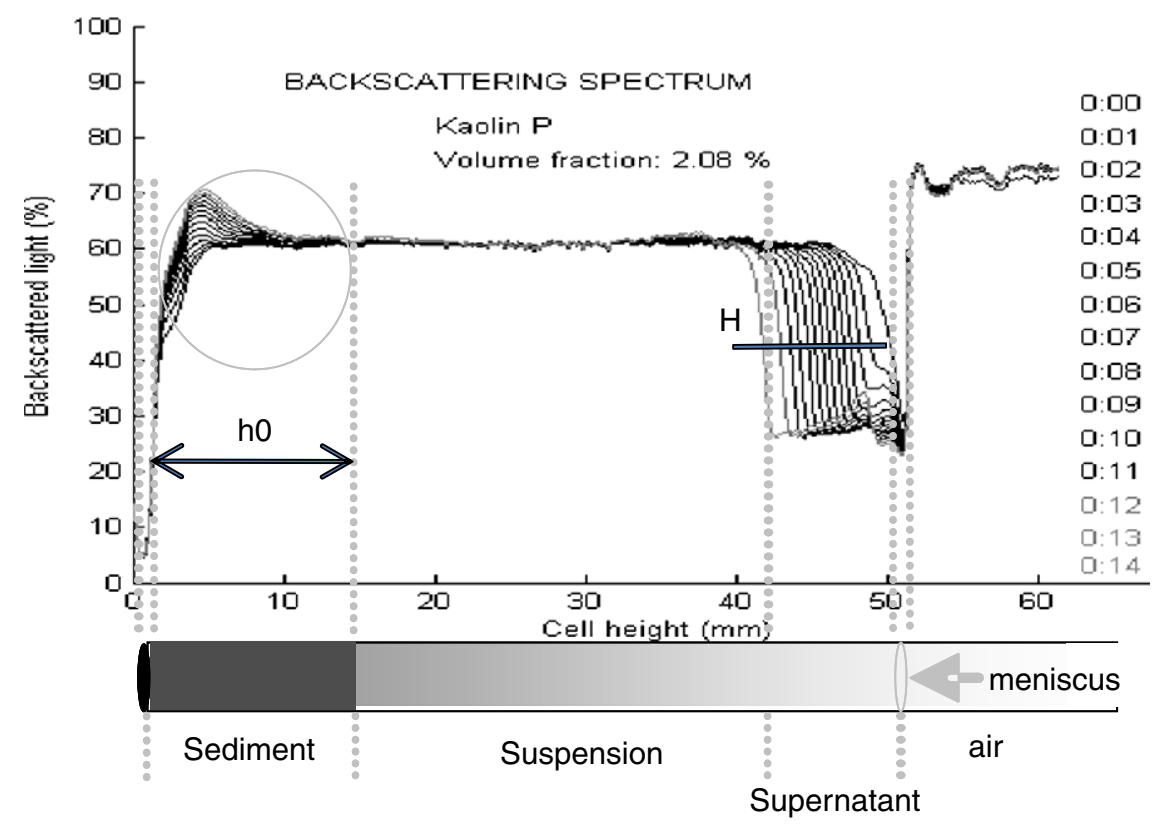

Fig. 2. An example of sedimentation profiles. 


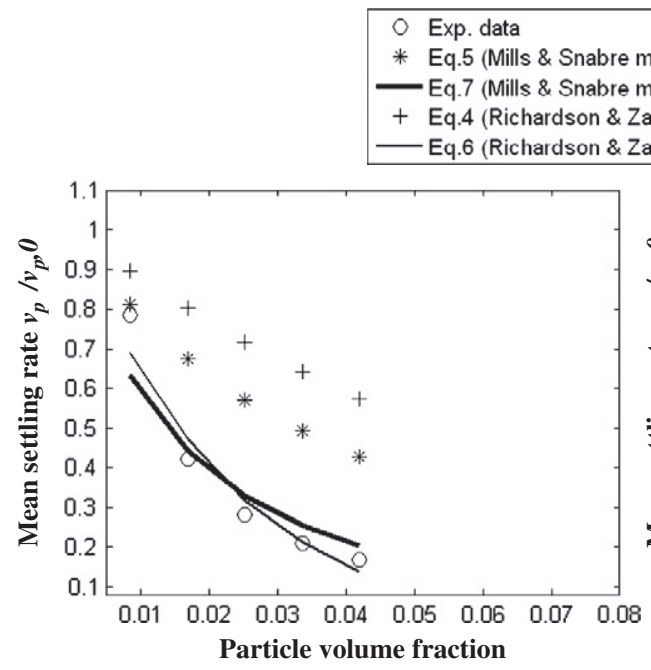

Exp. data

Eq.5 (Mills \& Snabre model for hard spheres)

(Mills \& Snabre model for cohesive particles)

Eq.4 (Richardson \& Zaki model for hard spheres)

Eq. 6 (Richardson \& Zaki model for cohesive particles)

Fig. 3. Mean settling rate in function of solid volume fraction for glass beads in water.

second step was the adjustment itself, i.e. to find the best parameters that are conform to the experimental data. Later, we will focus our development only on the determination of the parameter $k$. The determination of $n$ following the same way, it final values will be given in Table 3.

Let us consider Eq. (7). For very diluted suspension of cohesive particles, the expansion to the first order of the right member of Eq. (7) on the agglomerate effective volume fraction $\phi_{\text {ef }}$ gives:

$\frac{v_{p}}{v_{a}}=1-k \phi_{e f}$

Eq. (22) is the linear approximation of Eq. (7). It is valid for all materials provided that the agglomerate effective volume fraction is close to zero. A statistical analysis of the mean value of $\phi_{e f}$ for two small volumes of suspension in function of the number of primary particles allows the determination of $\phi_{e f}$ that is physically appropriate for Eq. (9). Despite the fact that it is more accurate to calculate $\phi_{e f}$ for each material in order to estimate $k$ we assume that $\phi_{e f}=0.01$ for all the systems studied. The main reason that supports this assumption is the fact that the variation of particles mean diameter does not exceed one order of magnitude for all the material investigated. The latter assumption

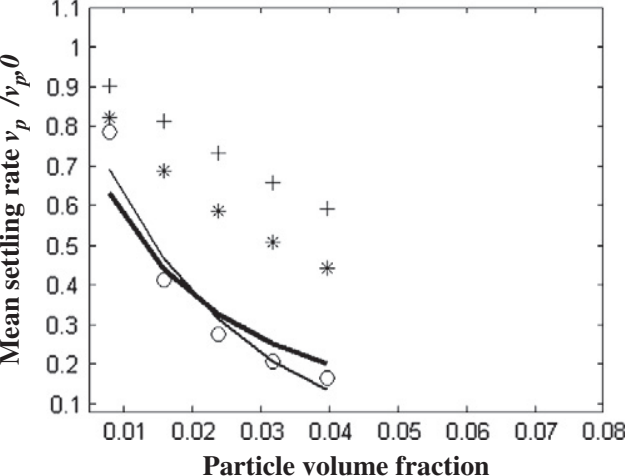

allows us to calculate the parameter $k$ from Eq. (22). We found the values of $k=26,58$, and 80 for glass beads, kaolin D and alumina suspensions, respectively. These values are one order of magnitude larger than the 4.6 value calculated for "large" monodisperse glass beads $(r=350 \mu \mathrm{m})$ in the glycerine-water mixtures [20] or the 5.4 value obtained for polystyrene spheres with $r=1.5 \mu \mathrm{m}$ in $10^{-3} \mathrm{M} \mathrm{NaCl}$ solution [21]. This remarkable value of $k$ will be discussed later.

The fitting parameters $R$ and $N$ were obtained by nonlinear optimization. The optimization procedure is based on Matlab function "Isqcurvefit" which solves the nonlinear data fitting problems in least square sense. Details regarding the adjustment parameters ( $R$ and $N$ ) and the parameters that best fit the experimental settling data together with the fractal dimension $D_{f}$ are mentioned in Table 2. The initialization values of $R$ and $N$ were obtained by considering the linear approximation of Eq. (6) in the frame work of very dilute suspension $\left(10^{-3}-10^{-2}\right.$ particles volume fraction). Table 2 also includes the interval within which the best parameters were found. This interval was expressed in terms of lower and upper bounds. The lower bound for $R$ and $N$ was the "primary particles radius $r$ " for each materials and " 1 primary particle" respectively. The upper bound for $R$ was the length of the linear agglomerate that consists of the upper bound of $N$ i.e. the total number of primary particles.

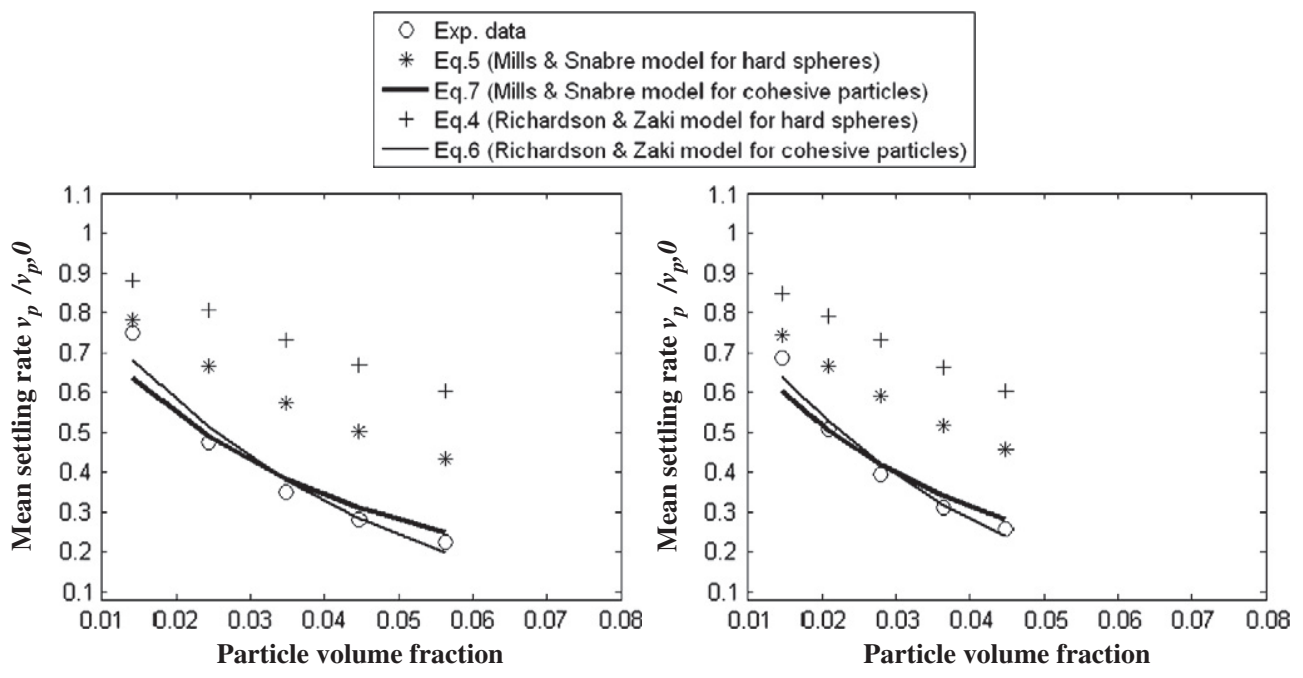

Fig. 4. Mean settling rate in function of solid volume fraction for kaolin D in water. 


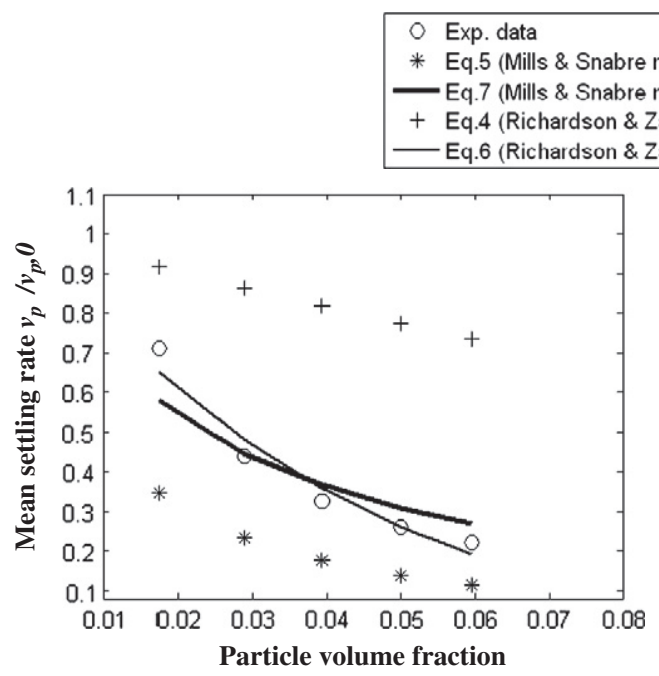

Exp. data

model for hard spheres

model for cohesive particles)

Eq.4 (Richardson \& Zaki model for hard spheres)

\& Zaki model for cohesive particles)

Fig. 5. Mean settling rate in function of solid volume fraction for alumina in water.

\subsection{Hydrodynamic characteristics}

In Eq. (9), $v_{a}$ is given by the $y$-intercept at $\phi=0$ in the Figs. $3-5$ representing the mean settling velocity in function of particles volume fraction. Using area equivalent mean diameter, we found that the Reynolds number Re is in the range of $\left[10^{-04}-10^{-02}\right]$. The range of Re obtained indicates that the laminar flow assumption is correct.

Drag coefficients $C_{D}$ were calculated for each suspension with different assumptions on agglomerate shape and permeability. We found that drag coefficients calculated using Eqs. (10)-(15) and that calculated using Eqs. (16)-(18) compare to each other with the relative error less than $6 \%$. The drag-corrective factor was found about unity $(\Omega=0.95)$ indicating that the agglomerates are almost impermeable. Hence, the obtained results expressed the influence of the external shape and the roughness of the body on the drag coefficient. We then calculated the spherical factor $\psi$ using the corrective drag coefficient $\Omega_{S}$. Poor sphericity was obtained. It is about $\psi=0.2$ for all agglomerates even for those composed of microspheres of noncohesive glass beads. This apparent contradiction will be discussed in Section 5. In order to determine which of the thermodynamic or the hydrodynamic forces was prevalent in examined suspensions, we calculated the Peclet number Pe using Eq. (20). The obtained values of $P e$ indicate that hydrodynamic force was dominant in both suspensions. The hydrodynamic force is 1 to 2 orders of magnitude in kaolin D and alumina suspensions compared to that of glass beads suspensions. The values $R_{e}, C_{D}, \Omega, \psi$ and $P e$ are summarized in Table 3.

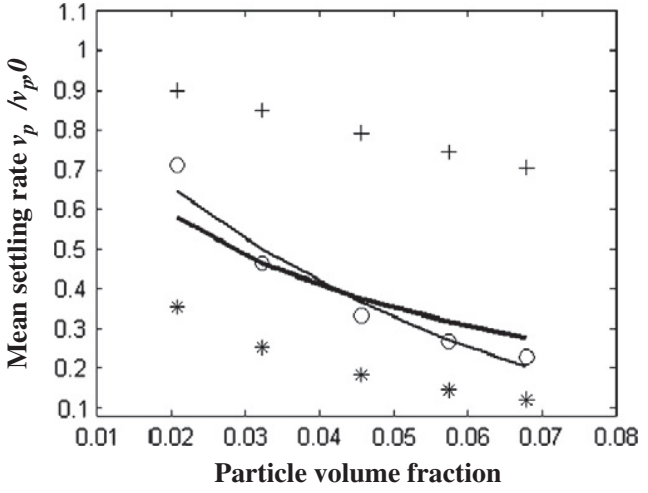

\section{Discussion}

Before developing this discussion, we should clarify the difference between agglomeration and aggregation, agglomerate and aggregate. The confusion is sometimes made in the use of these vocabulary. The key difference between agglomeration and aggregation processes is that the first one does not involve chemical reactions. The agglomeration process produces agglomerates and the process is entirely reversible because of the weakened nature of the connection (e.g. physicochemical interaction as van der Waals forces, hydrogen bond...) between primary particles inside the agglomerate. The aggregation process produces aggregates: the process is irreversible due to the strong nature of the connection (e.g. covalent chemical bond) between primary particles inside the aggregate. Moreover, the aggregation process is concerned with colloidal dispersion where the Brownian force is significant. In this study, we carefully avoided any chemical reaction between particles. The process involved then was the agglomeration and the objects produced are agglomerates.

In Table 2, the number of primary particles $N$ in the agglomerate increases as the primary particle size decreases indicating that for the same time of sedimentation, aggregation intensifies for fine cohesive particles. This tendency was confirmed by the obtained values of Peclet number. In both suspensions, gravity and hydrodynamic forces were predominant but the Brownian forces were not eliminated since the values of $P e$ were not infinite. The smaller the value of $P e$, the larger is the Brownian force. The latter in turn acts on small particles to favor collision and agglomeration. The obtained agglomerates were

Table 2

Detailed initialization of the optimization and the best adjustment parameters with the corresponding fractal dimension.

\begin{tabular}{|c|c|c|c|c|c|c|c|c|c|c|c|c|c|}
\hline & & \multicolumn{4}{|c|}{ Glass beads } & \multicolumn{4}{|l|}{ Kaolin D } & \multicolumn{4}{|l|}{ Alumina } \\
\hline & & \multicolumn{2}{|l|}{$3.5 \%$} & \multicolumn{2}{|l|}{$5.7 \%$} & \multicolumn{2}{|l|}{$3.5 \%$} & \multicolumn{2}{|l|}{$5.7 \%$} & \multicolumn{2}{|l|}{$3.5 \%$} & \multicolumn{2}{|l|}{$5.7 \%$} \\
\hline & & $\mathrm{R}(\mu \mathrm{m})$ & $\mathrm{N}$ & $\mathrm{R}(\mu \mathrm{m})$ & $\mathrm{N}$ & $\mathrm{R}(\mu \mathrm{m})$ & $\mathrm{N}$ & $\mathrm{R}(\mu \mathrm{m})$ & $\mathrm{N}$ & $\mathrm{R}(\mu \mathrm{m})$ & $\mathrm{N}$ & $\mathrm{R}(\mu \mathrm{m})$ & $\mathrm{N}$ \\
\hline Initialization & & 164 & 5400 & 164 & 5400 & 164 & 5400 & 164 & 5400 & 164 & 5400 & 164 & 5400 \\
\hline Lower bound & & 21.6 & 1 & 21.6 & 1 & 6.9 & 1 & 6.9 & 1 & 2.4 & 1 & 2.4 & 1 \\
\hline Upper bound & & $2.3 \mathrm{E}+10$ & $3.8 \mathrm{E}+09$ & $2.3 \mathrm{E}+10$ & $3.8 \mathrm{E}+09$ & $2.3 \mathrm{E}+10$ & $3.8 \mathrm{E}+09$ & $2.3 \mathrm{E}+10$ & $3.8 \mathrm{E}+09$ & $2.3 \mathrm{E}+10$ & $3.8 \mathrm{E}+09$ & $2.3 \mathrm{E}+10$ & $3.8 \mathrm{E}+09$ \\
\hline \multirow[t]{2}{*}{ Best adjustment } & Eq. (6) & $\begin{array}{l}364 \\
n=13\end{array}$ & $\begin{array}{l}1425 \\
n=13\end{array}$ & $\begin{array}{l}370 \\
n=13\end{array}$ & $\begin{array}{l}1393 \\
n=13\end{array}$ & $\begin{array}{l}173 \\
n=9\end{array}$ & $\begin{array}{l}5396 \\
n=9\end{array}$ & $\begin{array}{l}169 \\
n=11\end{array}$ & $\begin{array}{l}5400 \\
n=11\end{array}$ & $\begin{array}{l}160 \\
n=5\end{array}$ & $\begin{array}{l}136270 \\
n=5\end{array}$ & $\begin{array}{l}160 \\
n=5\end{array}$ & $\begin{array}{l}160670 \\
n=5\end{array}$ \\
\hline & Eq. (7) & $\begin{array}{l}353 \\
k=26\end{array}$ & $\begin{array}{l}1774 \\
k=26\end{array}$ & $\begin{array}{l}358 \\
k=26\end{array}$ & $\begin{array}{l}1724 \\
k=26\end{array}$ & $\begin{array}{l}164 \\
k=18\end{array}$ & $\begin{array}{l}6889 \\
k=18\end{array}$ & $\begin{array}{l}164 \\
k=21\end{array}$ & $\begin{array}{l}1077 \\
k=21\end{array}$ & $\begin{array}{l}100 \\
k=80\end{array}$ & $\begin{array}{l}1119700 \\
k=80\end{array}$ & $\begin{array}{l}100 \\
k=80\end{array}$ & $\begin{array}{l}1357300 \\
k=81\end{array}$ \\
\hline \multirow[t]{2}{*}{ Fractal dimension } & Eq. (6) & 2.6 & & 2.6 & & 2.7 & & 2.7 & & 2.7 & & 2.7 & \\
\hline & Eq. (7) & 2.7 & & 2.7 & & 2.8 & & 2.8 & & 3.5 & & 3.6 & \\
\hline
\end{tabular}


Table 3

Reynolds and Peclet numbers with the corresponding drag coefficients and the spherical factor of agglomerates.

\begin{tabular}{|c|c|c|c|c|c|c|c|c|c|c|}
\hline & \multirow{3}{*}{$\begin{array}{l}\text { Reynolds number } \\
\text { Re Eq. (9) }\end{array}$} & \multirow{3}{*}{$\begin{array}{l}\text { Peclet number } \\
\text { Pe Eq. (20) }\end{array}$} & \multicolumn{3}{|c|}{ Drag corrective coefficient $\Omega$} & \multicolumn{4}{|c|}{ Drag coefficients $C_{D}$ assuming that } & \multirow{3}{*}{$\begin{array}{l}\text { Spherical } \\
\text { factor } \psi \\
\text { Eq. (19) }\end{array}$} \\
\hline & & & \multicolumn{2}{|c|}{ Eqs. (12)-(15) } & \multirow[t]{2}{*}{$\begin{array}{l}\text { Eqs. (17) } \\
\text { and (18) }\end{array}$} & \multirow{2}{*}{$\begin{array}{l}\text { Spherical and } \\
\text { impermeable } \\
\text { aggregates } \\
\text { Eq. (10) }\end{array}$} & \multicolumn{2}{|c|}{$\begin{array}{l}\text { Spherical and } \\
\text { permeable aggregates } \\
\text { Eqs. (11)-(15) }\end{array}$} & \multirow{2}{*}{$\begin{array}{l}\text { Spherical and } \\
\text { permeable } \\
\text { aggregates } \\
\text { Eqs. (16)-(18) }\end{array}$} & \\
\hline & & & $3.5 \%$ & $\overline{5.7 \%}$ & & & $3.5 \%$ & $5.7 \%$ & & \\
\hline Glass beads & $2.9 \mathrm{E}-03$ & $2.6 \mathrm{E}+05$ & 0.8 & 0.9 & 1.0 & $8.3 \mathrm{E}+03$ & $7.0 \mathrm{E}+03$ & $7.5 \mathrm{E}+03$ & $7.9 \mathrm{E}+03$ & 0.2 \\
\hline Kaolin D & $8.1 \mathrm{E}-04$ & $2.3 \mathrm{E}+04$ & 0.9 & 1.0 & 1.0 & $3.0 \mathrm{E}+04$ & $2.8 \mathrm{E}+04$ & $2.8 \mathrm{E}+04$ & $2.9 \mathrm{E}+04$ & 0.2 \\
\hline Alumina & $6.9 \mathrm{E}-04$ & $5.3 \mathrm{E}+03$ & 0.9 & 0.9 & 1.0 & $3.5 \mathrm{E}+04$ & $3.1 \mathrm{E}+04$ & $3.2 \mathrm{E}+04$ & $3.4 \mathrm{E}+04$ & 0.2 \\
\hline
\end{tabular}

not spherical and impermeable with fractal dimension in the range of $2.5<D_{f}<2.7$. For other systems where primary particles aggregate, it has been established that such fractal dimension implies the diffusion limited particle-cluster aggregation (DLPCA). The DLPCA model of aggregation often occurs when the initial sample of suspension contains dissimilar (small and coarse) primary particles. That is the case in the systems considered in this study. By analogy with the aggregated systems, the mechanism of agglomeration could be described as follows: the small particles diffused in all directions as the Brownian forces acted on them. The coarse particles settled without diffusing. During the diffusion of small particles, they may collide with the coarse particles and some of them may stick onto them. The van der Waals forces act as the sticker when they get closer. The mechanism is called "diffusion limited particle-agglomerate agglomeration".

According to the work of [22], the Brownian forces $(P e=850)$ smoothens the discontinuities at the interfaces. The interface becomes the interphase with a progressive gradient of concentration. In this work, we observed this progressive gradient of concentration at each interface instead of a sudden cut-off. The values of $P e$ obtained (Table 2) were in very good agreement with the experimental observations.

Gruy and Cugniet [15] studied the hydrodynamics of the small aggregate. They found that porosity and permeability are properties without real meaning for the smallest aggregates $(\mathrm{N}<11)$. They also indicate that for relatively large aggregates $\left(30<\mathrm{N}<100, D_{f}=2.5\right)$ the effect of porosity on drag coefficient is negligible. These conclusions seems to be valid for very large agglomerate $(N=1,425,5,396$ or 136,270 , with $2.5<D_{f}<2.7$ ) for which the corrective drag coefficient is very close to unity $(\Omega=0.95)$.

The point that underpins the large value of $k$ is the low sphericity of the agglomerate. The spherical factor $\psi$ is found equal to 0.2 indicating definitely that the agglomerates have nonspherical shape. This sphericity factor is calculated using the structure factor $S$ and the fractal dimension of agglomerate. The assumption made in Eq. (7) that the volume of agglomerate can be approximated by the volume of sphere is false regarding this result.

Low sphericity amplified the angular dispersion of the fluid stream lines against the sedimentation direction, and hence, increased the value of $k$. On the other hand, the microspheres of glass beads were not cohesive. How could they agglomerate? The complementary experiments consisting of watering and dewatering the microspheres in the environmental scanning electron microscopy shows the formation of a water bridge between two particles at a certain distance. But the resulting adhesion force is not enough to agglomerate the microspheres. Thus, we suggest that the effect of concentration can lead to the formation of the "weak agglomerate" during sedimentation. At $3.5 \%$ or $5.7 \%$ volume fraction of microspheres, the mass sedimentation occurred in the settling column implying that some groups of microspheres settled together.

However for $k=80$, the fractal dimension of alumina agglomerates is estimated at about 3.5 using Eq. (7). This result did not correspond to any known theory of aggregation and brings two essential questions: the suitability of the model or/and the optical method used to study sedimentation reached its limits? For the first question, we showed that the assumption of the volume of agglomerate by the volume of sphere made the model inaccurate. The second question requires further developments.

\section{Conclusion}

We measured the settling velocity of macroscopic agglomerates consisting of a large number of primary particles in water. The Reynolds number was always small than 1 . We show that the large agglomerates formed during sedimentation were dense and impermeable for $2.5<D_{f}<2.7$. The high value of free parameters was underpinned by the low sphericity of the agglomerates. The modified models were found in good agreement with the experimental data for approximately the same values of $N$ and $R$ except for the Alumina suspensions, where Eq. (7) failed. This failure was explained as a consequence of assuming that the volume of agglomerate can be approximated by the volume of sphere. The results concerning fractal dimensions of agglomerates suggested that the mecanism of agglomeration was a diffusion limited particle-agglomerate agglomeration.

\section{Nomenclature}

$C_{D} \quad$ Drag coefficient $(-)$

$d_{s} \quad$ Area equivalent diameter $(\mathrm{m})$

$D_{o} \quad$ Diffusion coefficient $\left(\mathrm{m}^{2} / \mathrm{s}\right)$

$D_{f} \quad$ Fractal dimension of agglomerate $(-)$

E Shielding factor $(-)$

$f(\phi) \quad$ Particle flux function $\left(\mathrm{m} \mathrm{s}^{-1}\right)$

$h \quad$ Height of sample (suspension) in a column (m)

$k \quad$ Fitting parameter in Mills and Snabre model of sedimentation of hard spheres $(-)$

$k_{0} \quad$ Fractal pre-factor $(-)$

$L(\phi) \quad$ Happel function $(-)$

$n \quad$ Fitting parameter in Richardson and Zaki model of sedimentation of hard spheres $(-)$

$N \quad$ Number of primary particles per agglomerate $(-)$

$p \quad$ Agglomerate permeability at its surface $(-)$

$p_{e} \quad$ Number of Peclet $(-)$

$q \quad$ Normalize radius of Agglomerate (-)

$r \quad$ Primary particles radius $(\mathrm{m})$

$R \quad$ Agglomerate radius $(m)$

$R_{e, p} \quad$ Reynolds number of particle (-)

$R_{\mathrm{g}} \quad$ Radius of gyration of agglomerate (m)

$S \quad$ Structure factor of agglomerate $(-)$

$t \quad$ Time of sedimentation (s)

$v_{a} \quad$ Individual agglomerate settling velocity $\left(\mathrm{m} \mathrm{s}^{1}{ }^{1}\right)$

$v_{p} \quad$ Particles mean settling velocity $\left(\mathrm{m} \mathrm{s}^{-1}\right)$

$v_{p, 0} \quad$ Individual primary particle settling velocity $\left(\mathrm{m} \mathrm{s}^{-1}\right)$

$\alpha \quad$ Dispersion angle of liquid surrounding the particle against 
the vertical direction (radian)

$\Delta v_{p, 0} \quad$ Relative Stokes velocity $\left(\mathrm{m} \mathrm{s}^{-1}\right)$

$\phi \quad$ Volume fraction of particles (-)

$\phi_{\max } \quad$ Maximum volume fraction of particles (-)

$\phi_{0} \quad$ Initial particles volume fraction of homogeneous suspension (-)

$\phi_{e f} \quad$ Effective volume fraction of the agglomerate (-)

$\lambda \quad$ Wavelength of light ( $\mathrm{m}$ )

$\mu \quad$ Dynamic viscosity of liquid (Pas)

$\rho_{0} \quad$ Number of primary particles per unit volume of suspension or number density of particles $\left(\mathrm{m}^{-3}\right)$

$\rho_{l} \quad$ Liquid density $\left(\mathrm{Kg} \mathrm{m}^{-3}\right)$

$\Omega_{\text {perm }} \quad$ Drag corrective coefficient for permeable agglomerates (-)

$\Omega_{S} \quad$ Drag corrective coefficient based on structure of agglomerate $(-)$

$\psi \quad$ Spherical factor $(-)$

\section{References}

[1] G.C. Bushell, Y.D. Yan, D. Woodfield, J. Raper, R. Amal, On techniques for the measurement of the mass fractal dimension of agglomerates, Adv. Colloid Interface Sci. 95 (1) (2002) 1-50.

[2] B.C. Blakey, D.F. James, The viscous behavior and structure of aqueous suspensions of goethite, Colloids Surf. A: Physicochem. Eng. Aspects 231 (2003) 19-30.

[3] G.J. Kynch, A theory of sedimentation, Trans. Faraday Soc. 48 (1952) 166-176.

[4] G.K. Batchelor, Sedimentation in a dilute dispersion of spheres, J. Fluid Mech. 52 (1972) 245-268.

[5] A.B. Glendinning, W.B. Russel, A pairwise additive description of sedimentation and diffusion in concentrated suspensions of hard spheres, J. Colloid Interface Sci. 89 (1982) 124-143.
[6] R.W. O'Brien, A method for the calculation of the effective transport properties of suspensions of interacting particles, J. Fluid Mech. 91 (1979) 17-39.

[7] J.F. Richardson, W.N. Zaki, Sedimentation and fluidization, I Trans. Inst. Chem. Eng Lond. 32 (1954) 35-53.

[8] P. Mills, P. Snabre, Settling of suspension of hard spheres, Europhys. Lett. 25 (9) (1994) 651-656.

[9] J.M. Valverde, M.A.S. Quintanilla, A. Castellanos, P. Mills, The settling of fine cohesive powders, Europhys. Lett. 54 (3) (2001) 329-334.

[10] W.B. Russel, D.A. Saville, W.R. Schowalter, Colloidal Dispersion, Cambridge University Press, 1989, p. 525.

[11] G.K. Batchelor, C.S. Wen, Sedimentation of a dilute polydisperse system of an interacting spheres. 2. Numerical results, J. Fluid Mech. 124 (1982) 495-528.

[12] R.H. Davis, A. Acrivos, Sedimentation of noncolloidal particles at low Reynolds number, Ann. Rev. Fluid Mech. 17 (1985) 91-118.

[13] R.A. Dobbins, C.M. Megaridis, Absorption and scattering of light by polydisperse aggregates, Appl. Opt. 30 (33) (1991) 4747-4754.

[14] M. Vanni, Chem. Eng. Sci. 55 (2000) 685-694.

[15] F. Gruy, P. Cugniet, Experimental study of small aggregate settling, J. Colloid Interface Sci. 272 (2) (2004) 465-471.

[16] L. Gmachowski, J. Colloid Interface Sci. 178 (1996) 80.

[17] P. Bru, L. Brunel, H. Buron, I. Cayré, X. Ducarre, A. Fraux, O. Mengual, G. Meunier, A. de Sainte Marie, P. Snabre, Particle size and rapid stability analyses of concentrated dispersions: use of multiple light scattering technique ACS doc, 2004, pp. 1-15.

[18] O. Mengual, G. Meunier, I. Cayré, K. Puech, P. Snabre, TURBISCAN MA 2000: multiple light scattering measurement for concentrated emulsion and suspension stability analysis, Talanta 50 (1999) 445-456.

[19] P. Snabre, A. Arhaliass, Anisotropic scattering of light in random media: incoherent backscattered spotlight, Appl. Opt. 37 (18) (1998) 4017-4026.

[20] T.J. Hanratty, A. Bandukwala, Fluidization and sedimentation of spherical particles, AIChe J. 3 (1957) 293-299.

[21] R. Buscall, J.W. Goodwin, R.H. Ottewill, T.F. Tadros, The settling of particles through Newtonian and non Newtonian media, J. Colloid Interface Sci. 85 (78-86) (1982).

[22] F.M. Auzerais, R. Jakson, W.B. Russel, The resolution of shocks and the effects of compressible sediments on transient settling, J. Fluid Mech. 195 (1988) 437-462. 